contain an identical alpha chain leads to stimulation of gonadal FSH receptors by supraphysiological TSH concentrations.

Case Report We present a 8.5 -year-old girl referred to endocrinologist due to obesity and growth retardation that have worsened in the past year. Medical history revealed breast growth without pubic and axillary hair at the age of 8 years and menarche at the age of 8.5 years. Physical examination: short stature and generalized obesity (height $110.2 \mathrm{~cm},-3.6$ SD; weight $40.3 \mathrm{~kg},+1.8 \mathrm{SD}$ ), bradycardia (58 bpm), edematous and dry skin, thin hair, hoarse voice, thelarche Tanner stage III and absence of galactorrhea, pubic and axillary hair. The thyroid gland was not palpable. Laboratory tests revealed severe primary hypothyroidism as part of autoimmune thyroiditis (fT4 $5.2 \mathrm{nmol} / \mathrm{L}$, ref. 11-19.5; TSH > 100 $\mathrm{mIJ} / \mathrm{L}$, ref. 0.05-4.8; anti-TPO $250 \mathrm{IJ} / \mathrm{mL}$, ref. < 4.3). US: hypoechoic, hypotrophic thyroid without focal changes. Elevated estradiol $(72 \mathrm{pmol} / \mathrm{L}$, ref. $<32 \mathrm{pmol} / \mathrm{L})$ and prolactin concentrations (45 ug/L, ref. $<20 \mathrm{ug} / \mathrm{L})$ with normal gonadotropins were detected. Other significant laboratory findings were macrocytic anemia, hypercholesterolemia and elevated $\mathrm{CK}$ and LDH concentrations. X-ray of the wrist showed a bone age of 6 years. Pelvic US: enlarged uterus with thickened endometrium $(5 \mathrm{~mm})$ and bilaterally enlarged multicystic ovaries.

Conclusion A diagnosis of VWGS was established and L-thyroxine replacement therapy was introduced. It resulted in normalization of laboratory findings, cessation of menstruation and regression of breast glandular tissue. In the following year her height increased for $15 \mathrm{~cm}$ and weight was reduced for $10 \mathrm{~kg}$.

\section{EXTREME GROWTH RETARDATION CAUSED BY PRIMARY HYPOTHYROIDISM}

G Krajinović ${ }^{\prime}$ D Mitrović Dittrich, M Stanić, I Krajinović. OB „.Dr.Josip Benčević Slavonski Brod

10.1136/archdischild-2021-europaediatrics.223

A twelve-year old girl was hospitalized bacause of extremly short stature. She was born from normal pregnancy and delivery weight was $3000 \mathrm{~g}$ and height $51 \mathrm{~cm}$. She was not ill. Her psychomotoric development was normal. At the age of seven she was $115 \mathrm{~cm}$ tall (3. ct), and now, at the age of twelve $118.5 \mathrm{~cm}$ ( $Z$ score -4.64). She did not visit her doctor at that period. She was extremely short, her skin was dry, she was amimic, bradycardial, she had slowed and irregular tooth growth, and she did not have any signs of pubertal development.

In laboratory test: fT4 $<0.4 \mathrm{ng} / \mathrm{dl}$, fT3-<0.1 $\mathrm{pg} / \mathrm{ml}$, $\mathrm{TSH}>100 \mathrm{uUI} / \mathrm{ml}$, high levels of cholesterol, anemia, high levels of AST, ALT, CK, pleural and pericardiac effusion. Bone maturity matched that of a six-year old. ITT showed low production of growth hormone, and MRI of hypothalamic pituitary region was normal. We started treatment with levothyroxine, 50 ug per day, and vitamin D. After a few months her laboratory tests were normal. In the period of one year she has grown $11.5 \mathrm{~cm}$, she has gained $5 \mathrm{~kg}$, her bone maturity has improved and now matches that of a tenyear old, puberty started, her skin was normalized, her mood has improved, she is smiling more often and achieves better results at school. Her family is not cooperative so we included Social Welfare. We follow her development continuously

\section{Paediatric Gastroenterology, Hepatology and Nutrition}

\section{\begin{tabular}{|l|l}
224 & IMPAIRED SLEEP QUALITY IN CHILDREN WITH
\end{tabular} INFLAMMATORY BOWEL DISEASE PRESENT EVEN IN THE REMISSION PHASE AND ATTRIBUTING TO IMPAIRED HEALTH RELATED QUALITY OF LIFE}

Ivana Trivić*, Zrinjka Mišak, Sanja Kolaček, Iva Hojsak. Referral Centre for Paediatric Gastroenterology and Nutrition, Children's Hospital Zagreb

\subsection{6/archdischild-2021-europaediatrics.224}

Children with inflammatory bowel disease (IBD) have significantly lower health related quality of life (HRQoL) compared to healthy controls. HRQoL presents a broad, multidimensional concept compromising one's physical health, psychological state, level of independence, social relationships, personal beliefs and relationship to the environment. Good sleep is essential in maintaining health and quality of life (QoL) and plays a role in regulation of immune and neuroendocrine system. The aim of our study was to evaluate the relationship between sleep quality and HRQoL in children with IBD in remission.

A total of 33 paediatric IBD patients in remission (20 boys) aged $15.6 \pm 1.9$ years were included in the study (disease type: Crohn's disease (CD), $n=16$, ulcerative colitis (UC), $\mathrm{n}=15$, inflammatory bowel disease-unclassified (IBD-U), $\mathrm{n}=2$ ). Sleep quality was assessed using the Pittsburgh Sleep Quality Index (PSQI) questionnaire, whilst HRQoL was assessed using IMPACT III questionnaire. Moreover, patients wore a triaxial accelerometer for five consecutive days for objective PA quantification. Anthropometric data and inflammatory markers' values such as C-reactive protein (CRP), erythrocyte sedimentation rate (ESR) and faecal calprotectin values were recorded.

Prevalence of impaired sleep quality (PSQI $>5$ ) was 36.4\%, with mean PSQI score 4.64 \pm 2.21 . Highest mean scores were recorded in the sleep duration (mean score 1.06 \pm 0.99 ), sleep disturbance (mean score 1.06 \pm 0.35 ) and daytime dysfunction (mean score $1.00 \pm 0.79$ ) components of the questionnaire.

Mean IMPACT III score was $146.36 \pm 17.24$. On average, patients spent 38 minutes in moderate-to-vigorous physical activity (MVPA), and 198 minutes in light physical activity (LPA) per day. PSQI score negatively correlated with IMPACT III score (coef. $-0.446, \mathrm{p}<0.01$ ); meaning that the more significantly impaired sleep quality the more impaired QoL; and with time spent in LPA (coef. $-0.482, \mathrm{p}<0.01$ ). Interestingly, faecal calprotectin only positively correlated with sleep disturbance score (coef. 0.352, p =0.048), but had no significant correlation with the total PSQI score. No correlation was found between anthropometric and other laboratory parameters, MVPA and PSQI and IMPACT III scores.

More than a third of paediatric IBD patients suffer from poor sleep quality even in the remission phase. Further studies 